\title{
The zebrafish cationic amino acid transporter/ glycoprotein-associated family: sequence and spatiotemporal distribution during development of the transport system $\mathbf{b}^{0,+}($ slc3a1/slc7a9)
}

\author{
Ståle Ellingsen • Shailesh Narawane $\cdot$ \\ Anders Fjose · Tiziano Verri · Ivar Rønnestad
}

Received: 5 January 2021 / Accepted: 29 June 2021 / Published online: 2 August 2021

(C) The Author(s) 2021

\begin{abstract}
System $b^{0,+}$ absorbs lysine, arginine, ornithine, and cystine, as well as some (large) neutral amino acids in the mammalian kidney and intestine. It is a heteromeric amino acid transporter made of the heavy subunit SLC3A1/rBAT and the light subunit SLC7A9/ $/ b^{0,+}$ AT. Mutations in these two genes can cause cystinuria in mammals. To extend information on this transport system to teleost fish, we focused on the slc3al and slc7a9 genes by performing comparative and phylogenetic sequence analysis, investigating gene conservation during evolution (synteny), and defining early expression patterns during zebrafish
\end{abstract}

Ståle Ellingsen and Shailesh Narawane shared first authorship.

Supplementary Information The online version contains supplementary material available at https://doi. org/10.1007/s10695-021-00984-z.

S. Ellingsen $\cdot$ S. Narawane $\cdot$ A. Fjose

Department of Molecular Biology, University of Bergen, Postbox 7803, N-5020 Bergen, Norway

Present Address:

S. Ellingsen · A. Fjose $\cdot$ I. Rønnestad $(\bowtie)$

Department of Biological Sciences, University of Bergen,

Postbox 7803, N-5020 Bergen, Norway

e-mail: ivar.ronnestad@uib.no

T. Verri

Department of Biological and Environmental Sciences and Technologies, University of Salento, via Prov.le Lecce-Monteroni, 73100 Lecce, Italy
(Danio rerio) development. Notably, we found that slc $3 a 1$ and slc7a9 are non-duplicated in the zebrafish genome. Whole-mount in situ hybridization detected co-localized expression of slc3al and slc7a9 in pronephric ducts at $24 \mathrm{~h}$ post-fertilization and in the proximal convoluted tubule at 3 days post-fertilization (dpf). Notably, both the genes showed co-localized expression in epithelial cells in the gut primordium at $3 \mathrm{dpf}$ and in the intestine at $5 \mathrm{dpf}$ (onset of exogenous feeding). Taken together, these results highlight the value of slc $3 a l$ and $s l c 7 a 9$ as markers of zebrafish kidney and intestine development and show promise for establishing new zebrafish tools that can aid in the rapid screening(s) of substrates. Importantly, such studies will help clarify the complex interplay between the absorption of dibasic amino acids, cystine, and (large) neutral amino acids and the effect(s) of such nutrients on organismal growth.

Keywords Gut $\cdot$ Heteromeric amino acid transporters $\cdot$ Kidney $\cdot$ Proximal convoluted tubule · Proximal straight tubule

\section{Introduction}

In humans, the solute carrier 7 (SLC7) family consists of 15 members (Fotiadis et al. 2013). The encoded proteins are divided into two subgroups: cationic amino acid transporters and light subunits of heterodimeric amino acid transporters (HATs). 
HATs are characterized by broad substrate specificity toward several amino acid classes: neutral (SLC7A5, SLC7A8, SLC7A10, and SLC7A12), aromatic (SLC7A15), negatively charged (SLC7A11 and SLC7A13), and cationic plus neutral (SLC7A6, SLC7A7, and SLC7A9) amino acids (Chillaron et al. 2001; Bröer 2008; Fotiadis et al. 2013; Kandasamy et al. 2018). Each HAT consists of two subunits: light subunit and heavy subunit. Belonging to the solute carrier 3 (SLC3) family, the heavy subunit is a membrane glycoprotein that consists of a single transmembrane domain and a large extracellular domain. The subunits interact via a disulfide bridge between the two cysteine residues of the proteins forming HATs. The SLC3 family consists of two heavy chain members (SLC3A1 and SLC3A2) (Fotiadis et al. 2013), which are involved in the trafficking of the heteromeric complex to the plasma membrane, while light chains specifically catalyze the transport process (Bröer et al. 2001; Wagner et al. 2001; Chillaron et al. 2001; Bröer 2008; Fotiadis et al. 2013; Kandasamy et al. 2018).

HATs play important roles in membrane and cell transport. They play a key role in absorbing dietary proteins, with various transporters present on the apical and basolateral membranes of intestinal epithelial cells, to absorb amino acids from the intestinal lumen and release them into blood (Chillaron et al. 2001; Bröer 2008; Fotiadis et al. 2013; Kandasamy et al. 2018). HATs also have important functions in the kidney, where they are involved in the adjustment of amino acid levels in the ultrafiltrate and final urine (Chillaron et al. 2001; Bröer 2008; Fotiadis et al. 2013; Kandasamy et al. 2018). One such amino acid transport system is system $\mathrm{b}^{0,+}$, which consists of the subunits SLC3A1 and SLC7A9, otherwise known as rBAT and $\mathrm{b}^{0,+} \mathrm{AT}$, respectively (Bröer 2008). System $b^{0,+}$ (SLC3A1/SLC7A9) induces high-affinity, $\mathrm{Na}^{+}$-independent transport of lysine, arginine, ornithine (dibasic), and cysteine (neutral) amino acids in the kidney and intestine (Bertran et al. 1992, 1993; Magagnin et al. 1992; Lee et al. 1993; Palacin 1994; Chairoungdua et al. 1999; Mizoguchi et al. 2001; Pfeiffer et al. 1999). SLC3A1 mRNA is strongly expressed in the rabbit kidney and intestinal mucosa (Bertran et al. 1992; Magagnin et al. 1992). The rabbit SLC3A1 encodes a 77.8-KDa protein of 677 amino acids, with a single predicted transmembrane region (Bertran et al. 1992). SLC7A9, which was first isolated from humans and rats, encodes a $40 \mathrm{kDa}$ protein of 487 amino acids with 12 predicted transmembrane regions, and forms a heterodimer with SLC3A1 via a disulfide bridge (Chairoungdua et al. 1999; Pfeiffer et al. 1999). Initial studies showed that SLC7A9 and SLC3A1 co-localize to the apical membrane of the renal proximal tubule (Chairoungdua et al. 1999; Mizoguchi et al. 2001; Mora et al. 1996; Pfeiffer et al. 1999) and small intestinal epithelium (Dave et al. 2004).

SLC7A9/SLC3A1 collaborates with other systems (SLC7A7/SLC3A2 or SLC7A6/SLC3A2) for cystine and cationic amino acid transepithelial reabsorption; parallel and unidirectional neutral amino acid transport is required for this reabsorption (Bauch et al. 2003).

Initially, SLC3A1 was found to induce the exchange of dibasic (inward) with neutral (outward) amino acids through the membrane (Busch et al. 1994). Later, it was shown that the cytoplasmic tail and transmembrane region of SLC3A1 collectively play an important role in its functional interaction with SLC7A9 (Franca et al. 2005). SLC3A1 is quickly degraded in the absence of SLC7A9, while SLC7A9 is stable in the absence of SLC3A1 (Bauch and Verrey 2002). Both subunits depend on each other for apical surface expression, and when co-expressed, they link covalently and yield a fully glycosylated and more stable SLC3A1 (Bauch and Verrey 2002). SLC7A9 alone is adequate to catalyze transport (Reig et al. 2002), but there is also evidence that mutations in SLC $3 A 1$ may affect the transport properties of system $b^{0,+}$ (Pineda et al. 2004).

Mutations in SLC3A1 and SLC7A9 cause cystinuria (Calonge et al. 1995; Palacin 1994; Miyamoto et al. 1995; Bisceglia et al. 2001; Egoshi et al. 2000; Font et al. 2001; Dello Strologo et al. 2002). The clinical symptoms of cystinuria are related to nephrolithiasis, due to the precipitation of cystine in urine. Mutations in SLC3Al cause cystinuria type A, whereas mutations in SLC7A9 cause cystinuria type B (Dello Strologo et al. 2002). When the orthologous genes were knocked out in mice, the mutant displayed phenotypes similar to those in humans (Feliubadalo et al. 2003; Peters et al. 2003). Moreover, when a type AB cystinuria mouse model was generated upon crossing Slc $3 a 1^{-/-}$mice with $S l c 7 a 9^{-/-}$mice, the double heterozygous mice $\left(S l c 7 a 9^{+/-} / S l c 3 a I^{+/}\right)$exhibited lower expression of system $b^{0,+}$ and higher hyperexcretion 
of cystine than the single heterozygotes $\left(\mathrm{Slc}_{\mathrm{C}} \mathrm{9}^{+/-}\right)$ Slc $3 a 1^{+/+}$and $\left.S l c 7 a 9^{+/+} / S l c 3 a 1^{+/}\right)$, giving rise to lithiasis, thus showing that cystinuria has a digenic inheritance in this mouse model (Espino et al. 2015).

Information on Slc3a1 and Slc7a9 proteins in teleost fish is limited to a few species and organ systems. For instance, in adult Mozambique tilapia (Oreochromis mossambicus) intestine, differential mRNA expression of slc3al and slc7a9 was detected along the gastrointestinal tract. This expression is variably affected by water salinity (Nitzan et al. 2017), degree of completion of the food digestion process (Nitzan et al. 2017), and growth hormones (Petro-Sakuma et al. 2020). In addition, in turbot (Scophthalmus maximus) primary muscle cells, slc7a9 mRNA expression has been shown to decrease post soy phosphatidic acid administration (Wang et al. 2018). To date, very little is known about amino acid transporters in zebrafish (Danio rerio), despite the increasing relevance of this teleost fish model. In an attempt to fill these gaps, we hereby report a study on the system $\mathrm{b}^{0,+}$ in zebrafish, with emphasis on sequence analysis and spatiotemporal distribution in the developing kidney and gut. The gene identity of zebrafish vs. other teleost and higher vertebrate (human included) counterparts was assessed by means of synteny. The amino acid sequences of the proteins composing the zebrafish system $b^{0,+}$ were validated by comparison with their orthologs in vertebrates and construction of a phylogenetic tree. In situ hybridization at embryonic and early larval stages revealed segment-specific expression of slc3al and slc7a9 in the nephron. In addition, expression was observed in the gut, where the transcripts were localized to the intestinal epithelial cells. Taken together, these findings extend our knowledge of system $b^{0,+}$ in teleost fish by identifying the expression patterns of its components slc3al and slc7a9 in larval zebrafish. Thus, they serve as a starting point to fully clarify the role(s) of slc3al and slc7a9 in the development and function of the teleost fish kidney and intestine.

\section{Material and methods}

Zebrafish

Zebrafish were maintained and bred at the University of Bergen, as described elsewhere (Stuart et al.
1988). Zebrafish embryos were obtained via natural mating, and pigmentation was prevented by addition of $0.003 \%$ phenylthiourea to the E3 medium.

Sequence analysis

The nucleotide and protein sequences used in this study were obtained from Ensembl (http://www.ensem bl.org/index.html). The predicted transcripts used for generating the in situ probes were Ensembl Transcript ID: ENSDART00000132393 (Ensembl gene ID: ENSDARG00000017165) for slc3al and Ensembl Transcript ID: ENSDART00000100479 (Ensembl gene ID: ENSDARG00000005894) for slc7a9.

The SLC3A1/Slc3a1- and SLC7A9/Slc7a9-type amino acid sequences used for sequence comparison are shown in Table S1 (both Ensembl and UniProtKB peptide IDs reported; see also Appendix I) for each selected vertebrate species. Multiple sequence alignments were performed on orthologous proteins using ClustalO (https://www.ebi.ac.uk/Tools/msa/clustalo/) (Sievers et al. 2011), and neighbor-joining methodbased phylogenetic trees were constructed using MEGA7 (http://www.megasoftware.net).

Putative transmembrane domains were predicted using TMHMM 2.0 (http://www.cbs.dtu.dk/servi ces/TMHMM/), which is part of the Simple Modular Architecture Research Tool (SMART; http:// smart.embl-heidelberg.de/). Other domains were predicted using PFAM 32.0 (http://pfam.xfam.org/), which was also implemented in SMART. Potential $\mathrm{N}$-glycosylation, cyclic adenosine monophosphate/ cyclic guanosine monophosphate dependent protein kinase, and protein kinase $\mathrm{C}$ recognition sequences were identified using PROSITE 19.7 computational tools (http://www.expasy.org/prosite/).

Syntenic conservation of the zebrafish slc3al and $s l c 7 a 9$ genes with respect to other vertebrate orthologous genes was assessed using Genomicus (database version: 93.01; Nguyen et al. 2018) available online at http://genomicus.biologie.ens.fr/ genomicus-93.01/cgi-bin/search.pl using the search terms 'slc3a1' and 'slc7a9', respectively.

Protein modeling

SWISS-MODEL (Waterhouse et al. 2018) in the "Add Hetero Target" mode (https://swissmodel.expasy.org/ 
interactive) was used to predict the structure of the zebrafish Slc3a1 and Slc7a9 proteins using their primary sequences (UniProtKB peptide IDs: F1QEA9 and F1QGJ2, respectively; see Table S1). The search for templates directly targeted the human heteromeric amino acid transporter $b^{0,+}$ AT-rBAT complex bound to the arginine structure (Protein Data Bank Acc. No.: 6li9.1) (Yan et al. 2020) in the hetero-2-2-mer (i.e., heterotetramer made of two heterodimers) form (for details, see Fig. 1A; see also Fig. S1, Fig. S2 and Appendix I in the Supplementary Materials I), which was used as a template to build the model. SWISSMODEL view tools were also used to visualize the final three-dimensional structure (Fig. 1).

RNA probe preparation, DIG-labeling, and in situ hybridization

The in situ probes for slc $3 a 1$ and slc7a9 genes were isolated using PCR amplification with the primers listed in Table S2. The PCR amplicons were cloned into the pCRII-TOPO vector (Invitrogen, Carlsbad, USA). The obtained sequences were verified using sequencing.

Plasmid DNA was linearized with appropriate restriction endonucleases for $5 \mathrm{~h}$ at $37{ }^{\circ} \mathrm{C}$, purified using the QIAquick ${ }^{\circledR}$ Nucleotide Removal Kit (Qiagen, Hilden, Germany), following which the degree of linearization was examined on a $1 \%$ agarose gel. In vitro transcription to produce digoxygenin (DIG)labeled RNA probe was carried out as follows: linearized plasmids, $1 \mu \mathrm{g}$; DIG labeling mix (Roche, Mannheim, Germany) $2 \mu \mathrm{l}$; transcription buffer, $2 \mu \mathrm{l}$; RNase inhibitor (Roche), $1 \mu \mathrm{l}$; T7/Sp6 RNA polymerase (Roche), $2 \mu \mathrm{l}$; RNase-free double distilled $\mathrm{H}_{2} \mathrm{O}$ were combined to a final volume of $20 \mu \mathrm{l}$. The mixture was incubated at $37{ }^{\circ} \mathrm{C}$ for $2 \mathrm{~h}$. This was followed by DNase I treatment for $15 \mathrm{~min}$ at $37{ }^{\circ} \mathrm{C}$. Labeled RNA was purified using the RNeasy® Mini Kit (Qiagen), following which its probe length was

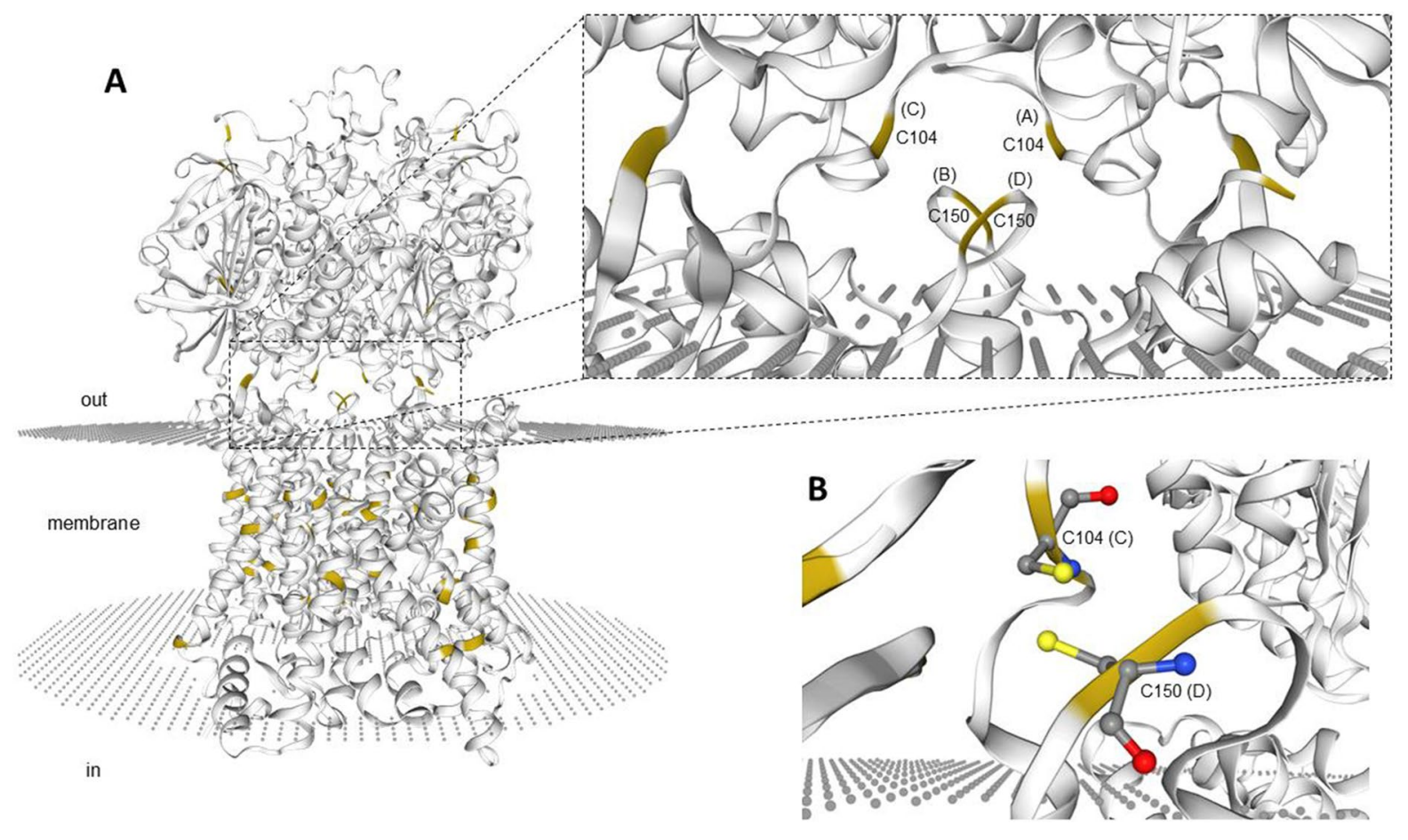

Fig. 1 (A) Three-dimensional appearance (lateral view) of the zebrafish Slc7a9( $b^{0,+}$ AT)-Slc3a1(rBAT) complex bound to arginine in the hetero-2-2-mer (i.e., heterotetramer made of 2 heterodimers) form and (B) snapshot of the putative disulfide bridge linking covalently one of the two heterodimers (i.e., the heterodimer made of chain C, Slc3a1 and chain D, Slc7a9).
The model was built using Protein Data Bank Acc. No. 6li9.1 as a template. Cysteine residues only are highlighted (yellow). A, chain A; B, chain B; C, chain C; D, chain D. Chains A and $\mathrm{C}$ refer to zebrafish Slc3a1; chains $\mathrm{B}$ and $\mathrm{D}$ refer to zebrafish Slc7a9. C104, cysteine residue $\mathrm{C}^{104}$ on chain C, Slc3a1; C150, cysteine residue $\mathrm{C}^{150}$ on chain $\mathrm{D}, \mathrm{Slc7}$ a9 
verified using agarose gel electrophoresis. It was then dissolved in $150 \mu \mathrm{l}$ hybridization buffer and stored at $-20{ }^{\circ} \mathrm{C}$ until use.

Whole-mount in situ hybridization was performed as previously described (Seo et al. 1998). Briefly, DIG-labeled antisense and sense (negative control) zebrafish slc7a9 and slc3al RNA probes were used. Embryos were fixed in $4 \%$ glutaraldehyde in $1 \times$ phosphate-buffered saline (PBS) and stained using nitroblue tetrazolium chloride and 5-bromo-4-chloro3'-indolyphosphate. For cryo cross-sections, the embryos stained using the in situ hybridization protocol were embedded in Tissue-Tek® (Sakura Finetek, Zoeterwoude, The Netherlands) after overnight incubation in $25 \%$ sucrose in $1 \times$ PBS. Sections $(20 \mu \mathrm{m}$ thick) were cut using a CM1800 Cryostat (Leica, Wetzlar, Germany) at $-20{ }^{\circ} \mathrm{C}$.

\section{Imaging}

In situ hybridization images were captured with a Leica M420 ${ }^{\mathrm{TM}}$ and Nikon EPI-FL3 ${ }^{\mathrm{TM}}$ microscope equipped with a micropublisher 5.0 RTV camera (QImaging, Tucson, AZ, USA). Figures were generated using CS2 Photoshop ${ }^{\mathrm{TM}}$ and Illustrator ${ }^{\mathrm{TM}}$ (Adobe San Jose, CA, USA).

\section{Ethical treatment of animals}

Fish were maintained and the experiments were conducted in compliance with the Norwegian Animal Welfare Act guidelines. No ethical permission was needed to be obtained for this study. According to the EU Directive 2010/63/EU on the protection of animals used for scientific purposes, implemented in Norwegian legislation as of 12.12.2014, early life stages of zebrafish are not protected as animals until they are capable of independent feeding, which is, 5 days post fertilization (dpf).

\section{Results}

Zebrafish system $b^{0+}$ is conserved among vertebrates

Detailed sequence analysis and interspecies comparison among vertebrates were performed to ascertain the identity of the predicted zebrafish system $b^{0+}$ components.

As assessed using GenBank database mining (December 2020), a single slc3al-type gene was found in the zebrafish genome (GRCz11 assembly) (Table 1). Multiple alignment of Slc3a1 protein sequences from zebrafish, fugu (fugu rubripes), medaka, tetraodon (spotted green pufferfish), frog (tropical clawed frog), chicken, cow, mouse, macaca (rhesus), and human was produced using ClustalO (Sievers et al. 2011) (Fig. S1). Phylogenetic analysis showed that the teleost fish cluster was separate from that of the higher vertebrates (Fig. 2A). To evaluate whether zebrafish slc3al is in conserved synteny with respect to its orthologs along the vertebrate scale, Genomicus analysis was performed. The analysis showed that slc3al lays within a strong syntenic region common to zebrafish (chromosome 13), fugu rubripes (scaffold_124), medaka (chromosome 15), spotted green pufferfish (chromosome 17), tropical clawed frog (chromosome GL172661.1), chicken (chromosome 3), cow (chromosome 11), mouse (chromosome 17), rhesus (chromosome 13), and human (chromosome 2) (for further details on this specific syntenic organization see Fig. S3). Zebrafish Slc3a1 was 59-66\% identical to that of the other fish species and $45-56 \%$ identical to that of higher vertebrates. As for the other vertebrates, the zebrafish Slc3a1 protein showed only one predicted transmembrane segment (amino acid 78 to amino acid 100) (Fig. S1), which consisted of 20 conserved hydrophobic amino acids flanked by glutamic acid (E) and serine (S) (conserved in all the vertebrates; Bertran et al. 1992). It was also observed that the cysteine (C) residues $\mathrm{C}^{104}, \mathrm{C}^{232}, \mathrm{C}^{259}, \mathrm{C}^{565}, \mathrm{C}^{656}, \mathrm{C}^{663}$, and the C-terminal $\mathrm{C}^{674}$ were conserved in higher vertebrates (Fig. S1). Notably, $\mathrm{C}^{114}$ in humans (corresponding to $\mathrm{C}^{104}$ in zebrafish), which is crucial for disulfide bridge formation between the light and heavy subunit chains of the heterodimer (Deora et al. 1998), was among the conserved cysteines. $\mathrm{C}^{104}$ in zebrafish is structurally related to this crucial disulfide bridge, as can be clearly seen in the structural representation of the zebrafish $b^{0,+}$ AT-rBAT complex in the hetero2-2-mer form (Fig. 1).

As assessed using GenBank database search (December 2020), a single slc7a9-type gene was found in the zebrafish genome (GRCz11 assembly) (Table 2). Multiple alignment of Slc7a9 proteins 


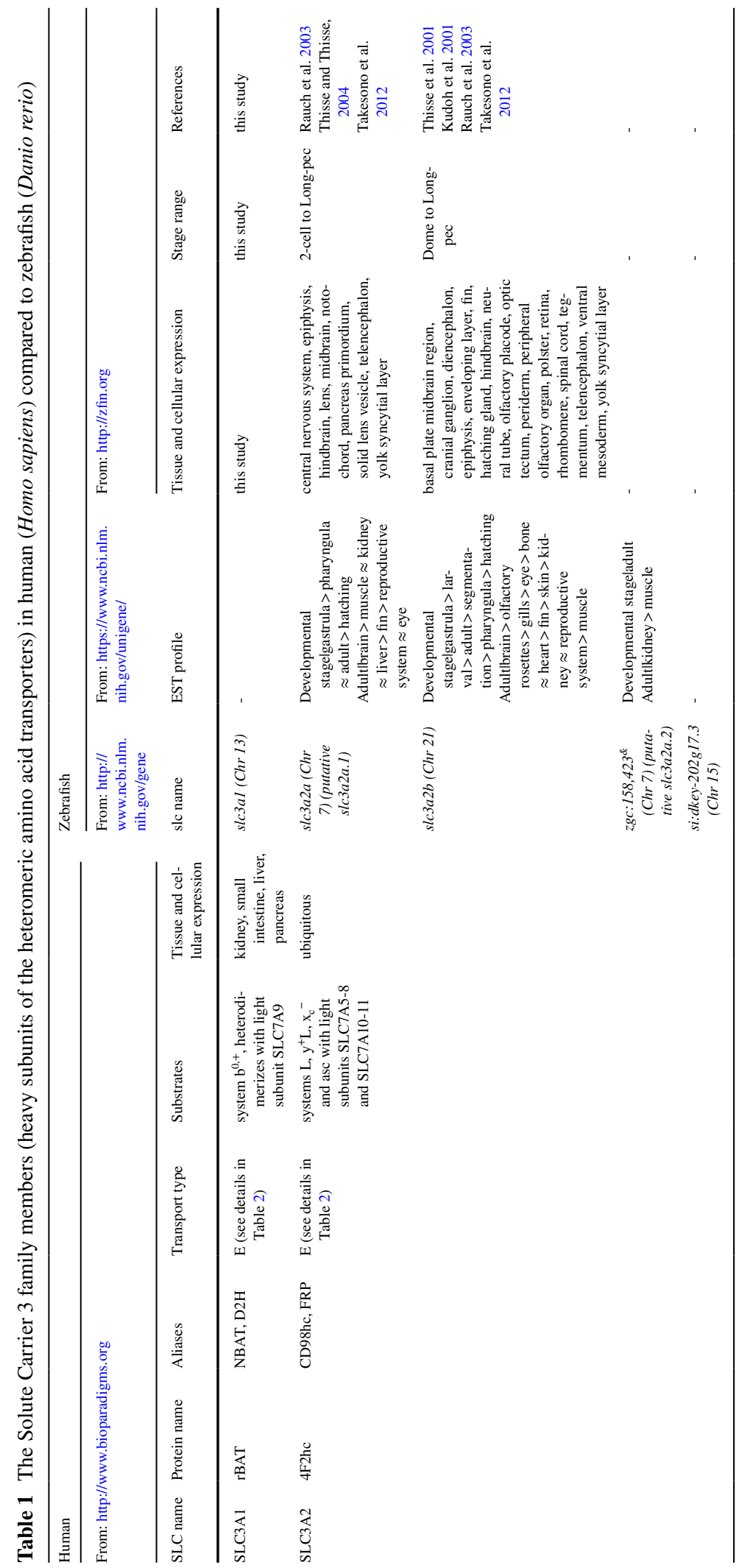

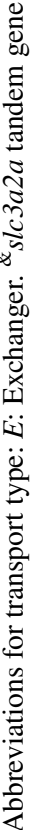


Fig. 2 Evolutionary relationships of taxa for Slc3a1 and Slc7a9. The evolutionary history was inferred using the Neighbor-Joining method (Saitou and Nei 1987). An optimal tree with sum of branch length $=1.67110532$ is shown. The percentage of replicate trees in which the associated taxa clustered together in the bootstrap test (1000 replicates) are shown next to the branches (Felsenstein 1985). The tree is drawn to scale, with branch lengths in the same units as those of the evolutionary distances used to infer the phylogenetic tree. The evolutionary distances were computed using the Poisson correction method (Zuckerkandl and Pauling 1965) and are in the units of the number of amino acid substitutions per site. The analysis involved 10 amino acid sequences. All positions containing gaps and missing data were eliminated. There were a total of 599 positions for Slc3a1 (A) and 471 positions for Slc7a9 (B) in the final dataset. Evolutionary analyses were conducted in MEGA7 (Kumar et al. 2016)
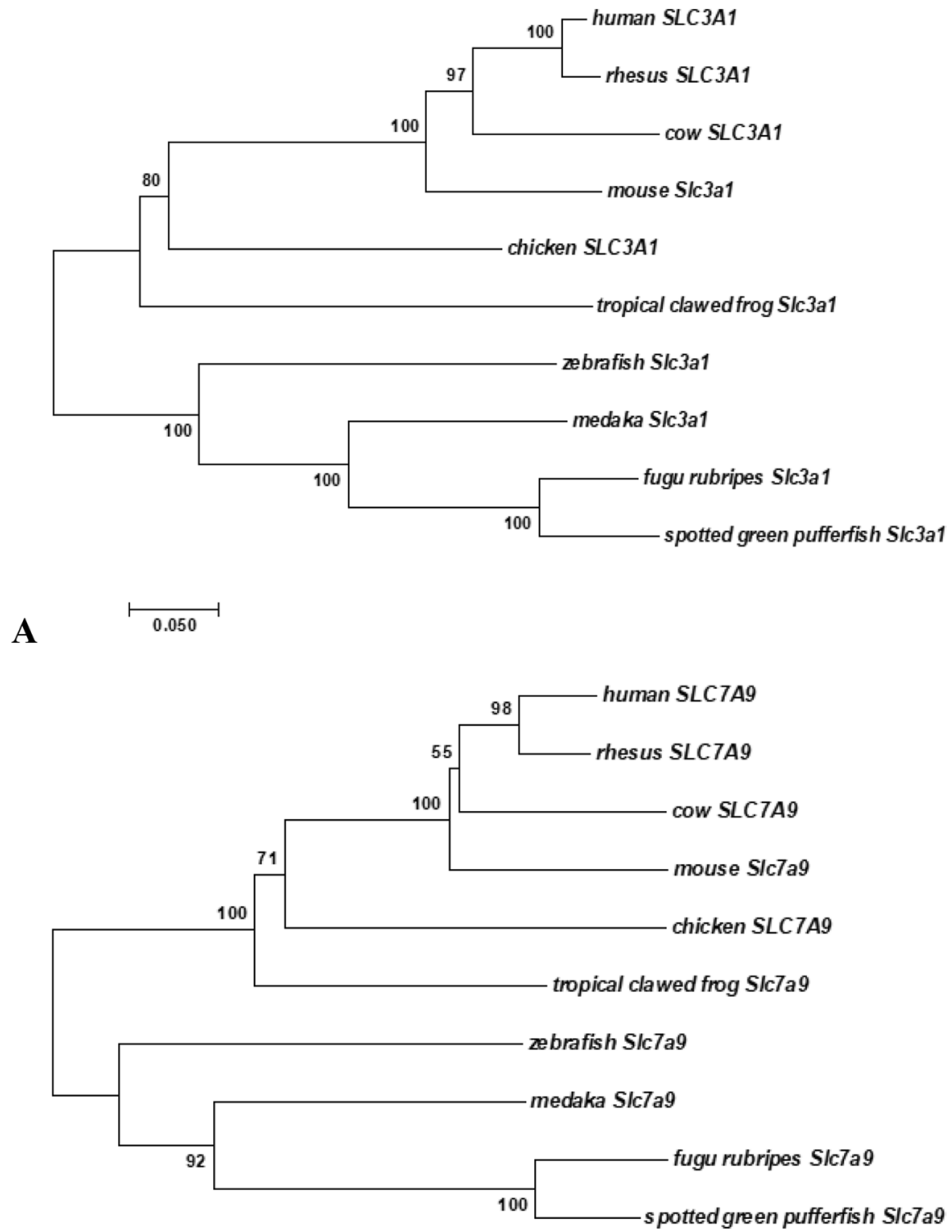

B

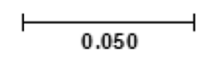

from zebrafish, fugu (fugu rubripes), medaka, tetraodon (spotted green pufferfish), frog (tropical clawed frog), chicken, cow, mouse, macaca (rhesus), and human was performed using ClustalO (Fig. S2). Phylogenetic analysis showed clustering of teleost fish Slc7a9, while Slc7a9 from the higher vertebrate branched together (Fig. 2B). To evaluate whether zebrafish slc7a9 showed conserved synteny with respect to its orthologs along the vertebrate scale, Genomicus analysis was performed. This analysis revealed that $\operatorname{slc7a9}$ lies within a syntenic region common to zebrafish (chromosome 7), fugu rubripes (scaffold_265), medaka (chromosome 3), spotted green pufferfish (chromosome 5), tropical clawed frog (chromosome GL1722806.1), chicken (chromosome 11), cow (chromosome 18), mouse (chromosome 7), rhesus (chromosome 19), and human (chromosome 19) (for further details on this specific syntenic organization, see Fig. S4). Zebrafish Slc7a9 was $68-75 \%$ identical to that of the other fish species and $67-69 \%$ 


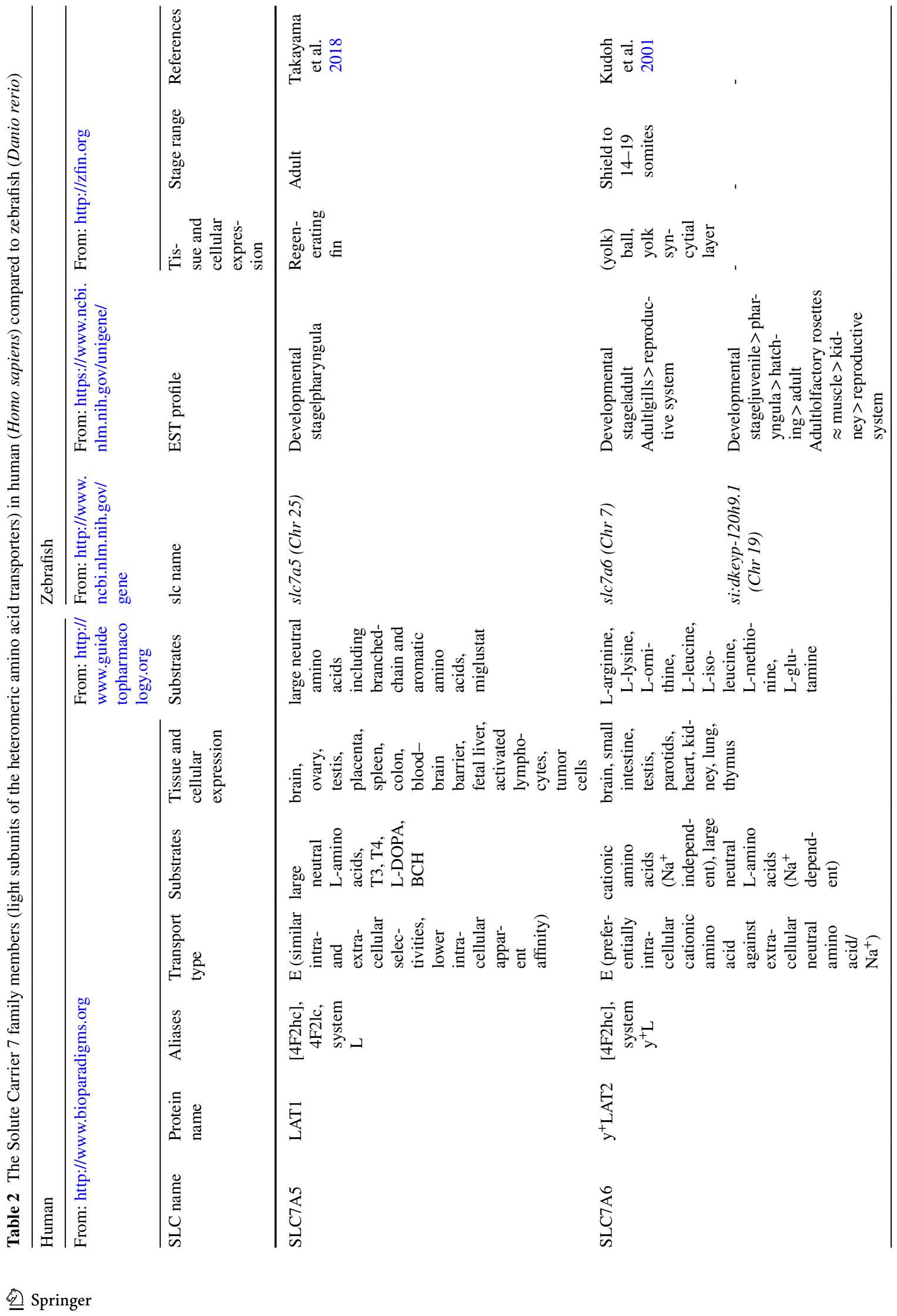




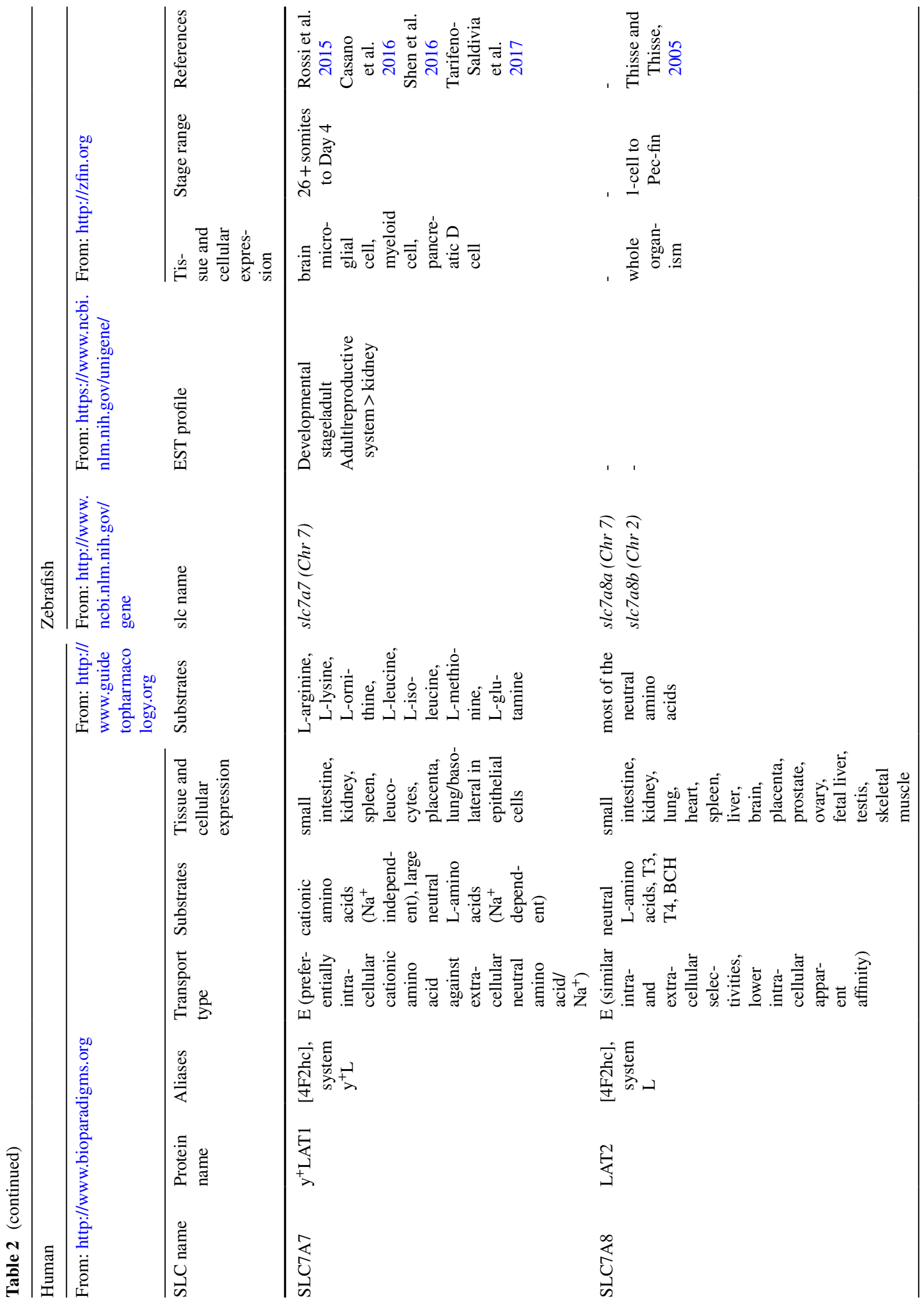




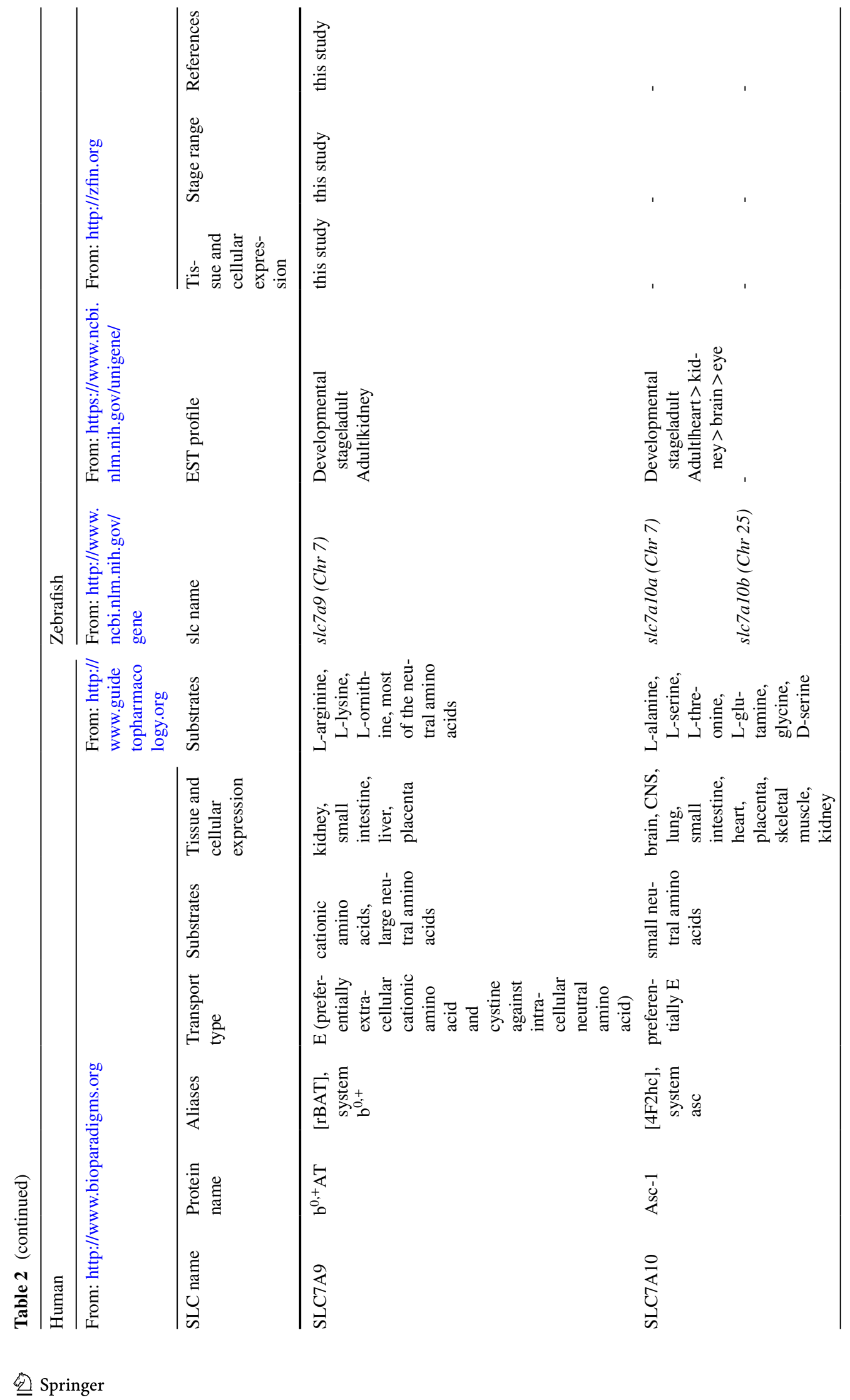




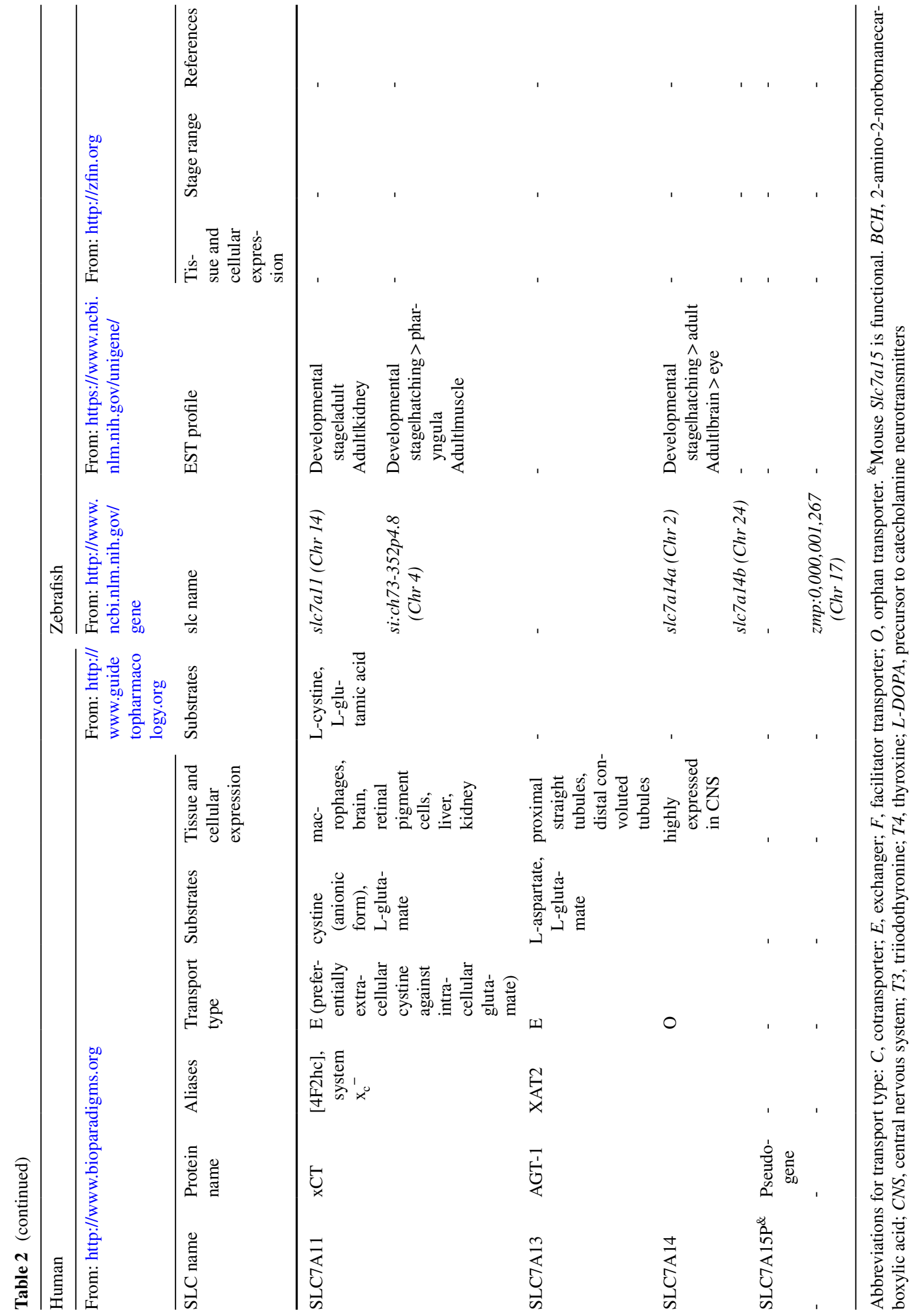




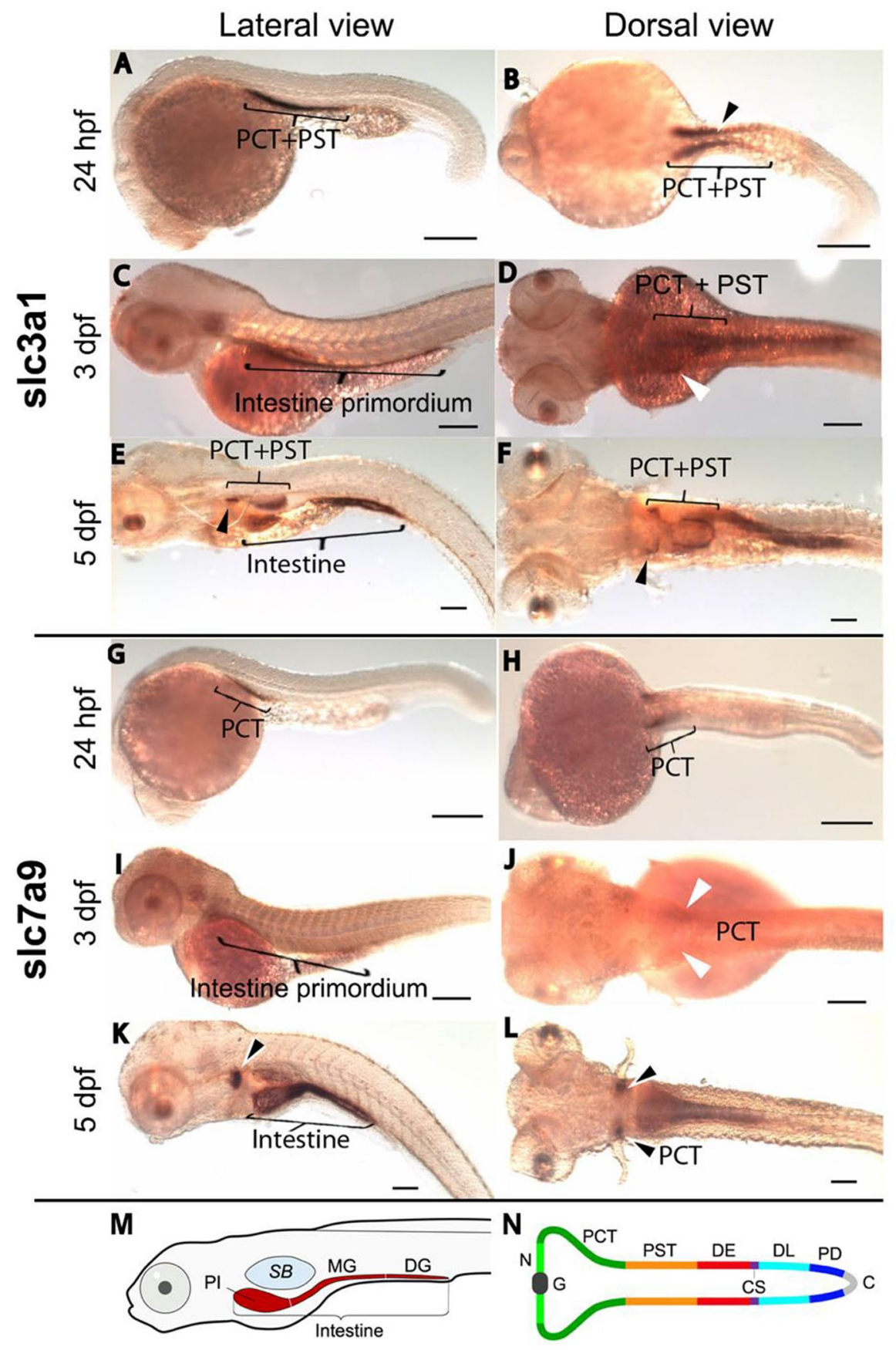

identical to that of higher vertebrates. As for the other vertebrates, zebrafish Slc7a9 exhibited 12 predicted transmembrane segments (Fig. S2). In addition, the peptide sequence alignment showed conservation of the cysteine residues $\mathrm{C}^{71}, \mathrm{C}^{78}, \mathrm{C}^{88}, \mathrm{C}^{150}, \mathrm{C}^{272}$, $\mathrm{C}^{327}$, and $\mathrm{C}^{446}$. A cysteine important for disulfide bridging between Slc7a9 and Slc3a1 (human $\mathrm{C}^{144}$, corresponding to zebrafish $\mathrm{C}^{150}$ ) was conserved in all the species investigated (Fig. S2). The zebrafish $\mathrm{C}^{150}$ residue is structurally related to this crucial disulfide bridge, as can be clearly seen from the structural representation of the zebrafish $b^{0,+}$ AT-rBAT complex in the hetero-2-2-mer form (Fig. 1). Alignment of human light chains revealed a $40 \%$ identity, with 
4Fig. 3 Spatiotemporal distribution of rBAT/slc3al and $b^{0,+} A T / s l c 7 a 9$. Whole-mount in situ hybridization of wildtype embryos. (A) Lateral view shows expression of slc3al in proximal convoluted tubule (PCT) and proximal straight tubule (PST) segments of the nephron at $24 \mathrm{hpf}$. (B) Dorsal view shows two parallel stripes of slc $3 a \mathrm{l}$ expression at $24 \mathrm{hpf}$ in the pronephros-spanning regions of PCT and PST. (C) Lateral view shows slc3al expression in intestinal primordium at $3 \mathrm{dpf}$. (D) slc $3 a 1$ expression at $3 \mathrm{dpf}$ is also observed in the PCT and PST in the dorsal view. (E-F) slc3al expression in the intestine, PCT, and PST at 5 dpf. (G) Lateral view and (H) dorsal view show the slc7a9 expression only in the PCT at 24 hpf. At $3 \mathrm{dpf}$, slc7a9 expression is seen in the intestinal primordium (I) and PCT (J). At $5 \mathrm{dpf}$, slc7a9 expression is seen in the PCT (K-L) and intestine (K-L). Arrowhead in B indicates putative region between PCT and PST. Arrowheads in $\mathbf{D}, \mathbf{E}, \mathbf{F}, \mathbf{J}, \mathbf{K}$, and $\mathbf{L}$ indicate PCT expression domains (scale bar: $100 \mu \mathrm{m})$. M Schematic lateral view of primordial intestine at $5 \mathrm{dpf}$; with proximal intestine (PI), midgut (MG) and distal gut (DG). SB, swim bladder. N Schematic dorsal view of nephrons with segments indicated: glomerolus $(\mathrm{G})$, neck $(\mathrm{N})$, distal early (DE), corpuscle of Stannius (CS), distal late (DL), and pronephric duct (PD), cloaca (C) (modified from Wingert et al. 2007). Abbreviations: hpf, hours post fertilization; dpf, days post fertilization

lower degrees of similarity toward both the $\mathrm{N}$ - and C-terminal ends (Wagner et al. 2001). Importantly, the C-terminal VPP $\left(\mathrm{V}^{480}, \mathrm{P}^{481}, \mathrm{P}^{482}\right)$ from human SLC7A9, which has been shown to be responsible for endoplasmic reticulum (ER)-to-Golgi trafficking (Sakamoto et al. 2009), was found to be conserved in the zebrafish Slc7a9 C-terminal (Fig. S2). Slc7a9 also exhibits the amino acid permease domain (Pfam domain PF00324, from amino acid 41 to amino acid 473, as shown in Fig. S2), which is involved in the transport of amino acids into cells (Weber et al. 1988).

Expression of $s l c 3 a 1$ and $s l c 7 a 9$ during zebrafish nephron development

We investigated the spatiotemporal distribution of slc3al and slc7a9 transcripts in the nephron and digestive system of wild-type zebrafish embryos using whole-mount in situ hybridization between $24 \mathrm{~h}$ post fertilization (hpf) and $5 \mathrm{dpf}$. Recent terminology for zebrafish nephron segmentation was adopted from Wingert and colleagues (Wingert et al. 2007). The first two zebrafish nephrons arise from the intermediate mesoderm and form eight distinct segments (going from proximal to distal): glomeruli, neck, proximal convoluted tubule (PCT), proximal straight tubule (PST), distal early, corpuscle of Stannius, distal late, and pronephric duct (Fig. 3M, N) (Wingert et al. 2007). This differentiation of segments helped us ascertain the specific nephron segments for HATs according to their expression patterns. At 24 hpf, both PCT and PST segments expressed slc3al (Fig. 3A), while slc7a9 was expressed only in the PCT (Fig. 3G). slc7a9 expression is similar to that of another solute carrier, slc20ala, involved in $\mathrm{Na}^{+} / \mathrm{PO}_{4}$ cotransport, which is also expressed in the PCT segment at 26 hpf (Wingert et al. 2007). For both slc3al and slc7a9, two distinct, paraxial expression domains (parallel to the midline) in the proximal segments of the pronephros were observed at $24 \mathrm{hpf}$ (Fig. 3B,H). The distinction between the PCT and PST at $24 \mathrm{hpf}$ was marked by shorter and more posteriorly restricted expression of $s l c 7 a 9$ limited to the PCT (Fig. 3G), as compared to that of slc3al, which extended more posteriorly and spanned both the PCT and PST regions (Fig. 3A). The occurrence of HATs at this early stage and in specific segments marks the maturation and differentiation of segment-specific epithelia before the onset of renal blood filtration, which occurs at 40 hpf (Drummond 2000, 2003, 2004, 2005). PCT coiling was observed between 72 and 144 hpf (Wingert et al. 2007); at $3 \mathrm{dpf}$, this was marked by the weak expression of slc3al (Fig. 3D) and slc7a9 (Fig. 3J). PCT coiling and positioning anterior to the PST was evident at $5 \mathrm{dpf}$ in the dorsal view, where slc3al was expressed in the PCT plus PST (Fig. 3F), while slc $7 a 9$ was restricted to the PCT (Fig. 3L). The segment identities of PCT and PST were assigned using the expression patterns previously determined for slc20ala (in PCT) and for trpm7 and slc13al (in PST) at $26 \mathrm{hpf}$ and 48-144 hpf, respectively (Wingert et al. 2007).

Expression of slc $3 a 1$ and slc $7 a 9$ during zebrafish intestine development

Although the zebrafish intestinal lumen starts forming at 26-52 hpf ( $\mathrm{Ng}$ et al. 2005), the expression of HATs in the intestinal primordium was observed much later, at $3 \mathrm{dpf}$ (Fig. 3C,I). Expression of slc3al (Fig. 3C) and slc7a9 (Fig. 3I) is marked by a line arising anteriorly from the pectoral fin bud posteriorly till the cloaca. By $74-76 \mathrm{hpf}$, the entire digestive tract is a hollow tube formed by epithelial cell polarization 
( $\mathrm{Ng}$ et al. 2005). At $5 \mathrm{dpf}$, the remodeling and differentiation of zebrafish intestinal epithelium takes place, the intestinal tract is segmented into the intestinal bulb, mid intestine, and posterior intestine $(\mathrm{Ng}$ et al. 2005), and the yolk is completely resorbed (Fig. 3E,K). At this stage, the larva is ready for exogenous feeding, which means it should start absorbing nutrients through the functional intestinal epithelium. Increased co-expression of slc3al (Fig. 3E) and slc $7 a 9$ (Fig. 3K) along the entire intestine marks this transition in nutrient supply.

slc $7 a 9$ and slc $3 a 1$ are expressed in kidney and intestine-polarized cells (nephron tubule cells and enterocytes)

To focus on the detailed position of slc $3 a l$ and slc7a9 expression in the nephron and the structural organization of the epithelial cell lining of the intestine, we generated serial transverse sections. Crosssections of the whole-mount in situ hybridized embryos revealed strong expression of slc $3 a 1$ along the anterior-posterior length of the nephron, ventral to the notochord and somites, and dorsal to the yolk at $24 \mathrm{hpf}$ (Fig. 4A). A similar position but weaker expression of slc7a9 was observed in the crosssection from the most anterior part of the nephron at $24 \mathrm{hpf}$ (Fig. 4B). slc3al was expressed in the PCT and PST segments of the pronephric ducts running ventral and parallel to the somite muscles at $5 \mathrm{dpf}$ (Fig. 4C). slc7a9 expression was similar to that of slc3al, but restricted to sections from the PCT region of the anterior nephrons (Fig. 4D). Coexpression of slc3al and slc7a9 in the PCT (Figs. 3, and 4) supports that slc $7 a 9$ and slc3al act together in the PCT region of zebrafish. At $3 \mathrm{dpf}$, both slc3al and slc7a9 showed similar expression domains in the intestine (Fig. 3C,I). Interestingly, the intestinal cryo cross-sections from $5 \mathrm{dpf}$ embryos revealed the localization of slc3al mRNAs to the luminal single layer of enterocytes (Fig. 4E-F, white arrowhead). This epithelial cellular mRNA localization was also clearly visible for slc $7 a 9$ at $5 \mathrm{dpf}$ (Fig. 4G-H, white arrowhead).

\section{Discussion}

Absorption of amino acids from the intestine and their reabsorption in the kidney to prevent urinary loss is highly relevant for protein synthesis, accretion, and body growth. This process is vital in case of essential amino acids, such as lysine. Notably, impairment of renal amino acid reabsorption leads to various types of aminoacidurias. In this study, we focused on the system $b^{0,+}$, which is involved in the transport of lysine, arginine, ornithine, and cystine. Our sequence comparison identified the zebrafish system $\mathrm{b}^{0,+}$ along with information on its syntenic conservation with functionally- and developmentallyrelated genes. Analysis of gene expression patterns at various stages revealed the nephron segment-specific and intestinal occurrence of both slc3al and slc7a9. Further analysis using transverse sections revealed system $b^{0,+}$ transcript localization in polarized intestinal epithelial cells.

System $\mathrm{b}^{0,+}$ protein sequences are evolutionarily conserved

System $b^{0,+}$ is involved in crucial functions of essential amino acid transport and is highly conserved from invertebrates to mammals. HATs have been shown to be functionally conserved throughout evolution from nematodes to mammals (Veljkovic et al. 2004). The membrane topology predictions for zebrafish slc $3 a 1$ and slc7a9 showed one and twelve transmembrane domains, respectively, which is in agreement with previous reports (Wagner et al. 2001). In addition, the cysteine residues involved in the formation of the disulfide bridge in HATs from higher vertebrates are conserved in the zebrafish system $\mathrm{b}^{0,+}$. Also, the C-terminus of $\mathrm{b}^{0+} \mathrm{AT}$ shows that the VPP motif $\left(\mathrm{V}^{480}, \mathrm{P}^{481}, \mathrm{P}^{482}\right)$ is conserved in zebrafish. This motif is reported to be responsible for trafficking of the heterodimer SLC3A1/SLC7A9 from the ER to the Golgi apparatus (Ganapathy 2009; Sakamoto et al. 2009). It is still unknown whether the VPP/ VVY C-terminal sequences in other light chains play a role in ER-Golgi trafficking of the respective heterodimers (Ganapathy 2009; Sakamoto et al. 2009) or if it exerts specificity of the light chain towards a particular heavy chain. Because of the conservation of the C-termini of light chains, common regulatory 

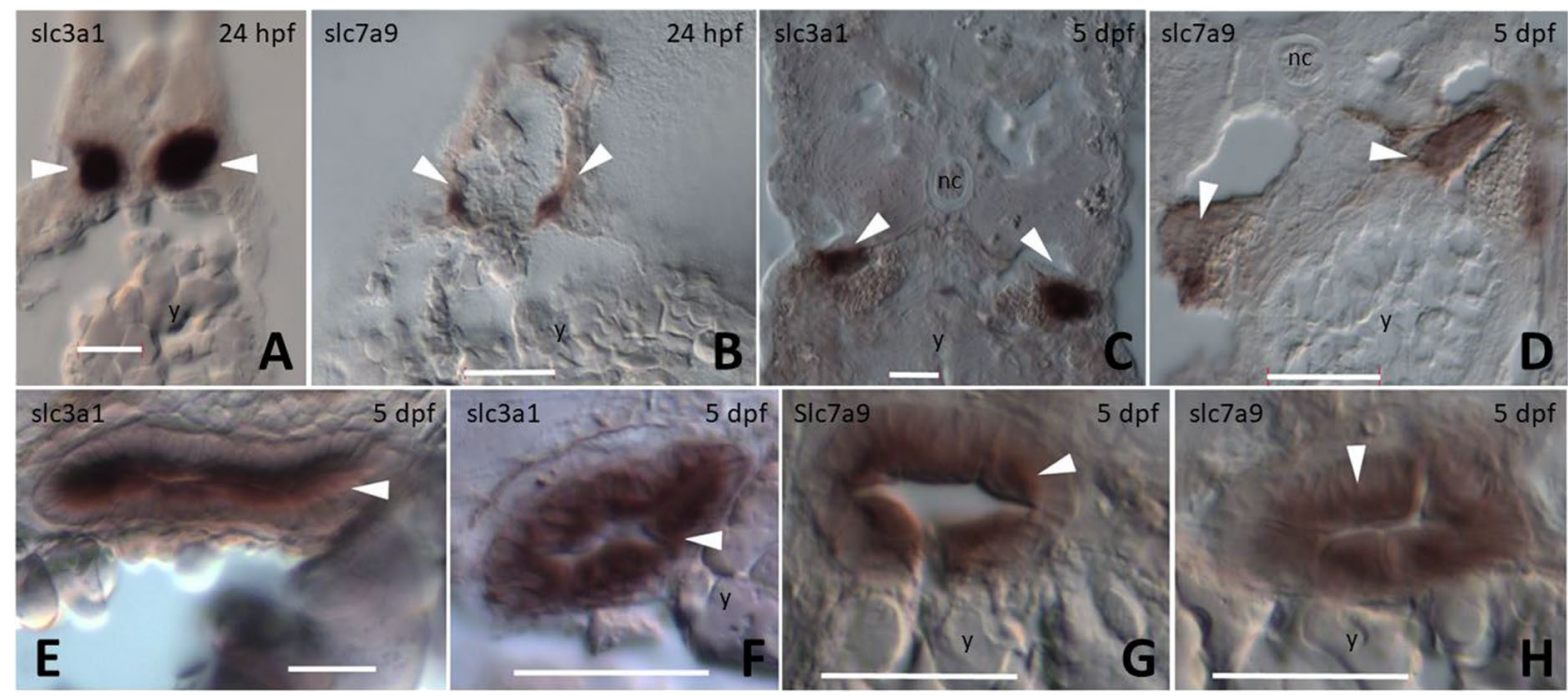

Fig. 4 Images of cryo cross-sections from whole-mount in situ hybridization for the genes slc3al and slc7a9. (A) slc3al and (B) slc7a9 expression in two distinct nephrons (white arrowheads) at 24 hpf. (C) slc $3 a 1$ and (D) slc7a9 expression in two distinct nephrons (white arrowheads) at $5 \mathrm{dpf}$. (E-F) slc3al and (G-H) slc7a9 intestinal cross-sections reveal the localiza-

tion of expression in enterocytes at $5 \mathrm{dpf}$ (white arrowheads). Scale bar: $20 \mu \mathrm{m}$. All sections were dorsal to the top and ventral to the bottom. Scale bar: $20 \mu \mathrm{m}$. Abbreviations: nc, notochord; y, yolk; hpf, hours post fertilization; dpf, days post fertilization

mechanisms involving C-termini action among HATs might be present, as proposed (Sakamoto et al. 2009).

On the other hand, the cysteine residue located at the C-terminal $\left(\mathrm{C}^{674}\right)$ of zebrafish Slc3a1 is fully conserved in higher vertebrates. This is in line with the observation that deletion of the human SLC3A1 C-terminal disulfide loop (residues 673-685) prevents maturation and prompts degradation of the transporter (Rius et al. 2016). Taken together, similar membrane topology and conservation of functionally vital residues and motifs confirmed the identities of the predicted zebrafish system $b^{0,+}$ orthologs.

slc3al and slc7a9 occur in a non-duplicated form in the zebrafish genome

Single slc3al- and slc7a9-type genes are present in the zebrafish genome. This was primarily concluded from the initial GenBank database mining and was subsequently confirmed by thorough and systematic consulting of other platforms and databases such as Ensembl and UniProt. As part of our strategy, we searched for genes/proteins and used the alignment tools associated (e.g., BLAST) to cross-check the sequence analysis. In addition, whenever possible

(e.g., in case of BLAST analysis at NCBI), not only the non-redundant or RefSeq Select or Reference sequence sections, but also more explorative sections, such as the Transcriptome Shotgun Assembly or the Expressed sequence tags sections, were systematically consulted. In this way, we thoroughly investigated the large family of sequences present in the various databases related to Slc3a1 and Slc7a9 in zebrafish, in order to fully assess the effective number of slc3al-and slc7a9-type genes and define the related Slc3a1- and Slc7a9-type proteins.

System $b^{0,+}$ is expressed in developing zebrafish kidney and intestine

We found that the system $b^{0+}$, which is involved in lysine, arginine, ornithine, and cystine transport, in addition to that of (large) neutral amino acids, is expressed in the developing nephron ( $24 \mathrm{hpf}$ ) much earlier than in the intestine ( $3 \mathrm{dpf}$ ). This indicates that the $b^{0+}$-mediated renal reabsorption of amino acids is activated earlier than intestinal absorption. This is possibly related to the close homeostatic control of the amino acid pool in the developing embryo, which includes recovery of important solutes from the 
pre-urine. Exogenous feeding starts later (after $5 \mathrm{dpf}$ ), and prior to this, the zebrafish acquire amino acids and other nutrients from the yolk as a sole source.

Both slc3al and slc7a9 show high levels of expression in the proximal tubule part of pronephros; however, differences in spatial distribution were detectable, with slc $7 a 9$ expression restricted to the PCT, while slc3al showed stronger expression in the PCT and PST. These differences in the pronephric distribution of expression in zebrafish are consistent with those reported in mice (Palacin et al. 2001) and Xenopus (Raciti et al. 2008). The overlap of slc3al-slc7a9 expression in the proximal tubule segments is in correlation with this heterodimer, which is responsible mainly for cystine transport from the kidney proximal tubule, as discussed by Fernandez et al. (2002). Since the light chain, i.e., slc $7 a 9$, is only present in the PCT region, whereas the heavy chain slc3al expression extends to the PST segment (Furriols et al. 1993), alternative light chain partners for slc3al and heavy chain partners for slc $7 a 9$ are likely to exist in the non-overlapping expression domains (Palacin et al. 2001). Preliminary data from morpholino knockdown experiments targeting slc7a9 might indicate that slc7a9 is important for proper formation of the PCT segment were morphants lacked the convolution of the proximal segment of the nephron (Supplementary Materials II). However, these results should be followed up with generation and analysis of a stable slc7a9 mutant zebrafish line (e.g., by utilizing Cas9CRISPR technology).

A gradual increase in the intestinal co-expression of slc $3 a 1$ and slc7a9 from 3 to $5 \mathrm{dpf}$ is in coordination with the functional maturity of the zebrafish intestine ( $\mathrm{Ng}$ et al. 2005; Verri et al. 2003). A stronger expression at $5 \mathrm{dpf}$ might be part of the preparations of the transport machinery for the onset of exogenous feeding since most of the yolk has been resorbed by this time.

This is the first report on the system $b^{0,+}$ being expressed in the developing kidney and intestine in zebrafish as early as $24 \mathrm{hpf}, 3 \mathrm{dpf}$, and $5 \mathrm{dpf}$.

Acknowledgements We thank Heikki Savolainen and Grigory Merkin for taking very good care of our zebrafish facility.

Author contribution SN, IR, AF, and SE conceived the project and planned the experiments; SN performed the experiments; all the authors discussed the results; SN, SE, IR, and TV prepared the figures; TV prepared the tables; all the authors wrote the manuscript and read and approved the final manuscript.

Funding Open access funding provided by University of Bergen (incl Haukeland University Hospital). This study was funded by the Research Council of Norway (RCN) under the NFR Strategic University Program (Project 174979/I30). IR also acknowledges funds from the RCN (Project 311627) and Mobility grants from the Meltzer Foundation and the University of Bergen.

Data availability All the data is available in the paper and the supplementary material (Supplementary Materials I and Supplementary Materials II).

Code availability Not applicable

\section{Declarations}

Ethics approval Fish were maintained and experiments were conducted in compliance with the Norwegian Animal Welfare Act guidelines. No ethical permission was needed to be obtained for this study. According to the EU Directive 2010/63/EU on the protection of animals used for scientific purposes, implemented in Norwegian legislation as of 12.12.2014, early life stages of zebrafish are not protected as animals until they are capable of independent feeding, which is 5 days post fertilization.

\section{Consent to participate Not applicable}

Consent for publication All the authors have approved the final manuscript.

Conflict of interest The authors declare no competing interests.

Open Access This article is licensed under a Creative Commons Attribution 4.0 International License, which permits use, sharing, adaptation, distribution and reproduction in any medium or format, as long as you give appropriate credit to the original author(s) and the source, provide a link to the Creative Commons licence, and indicate if changes were made. The images or other third party material in this article are included in the article's Creative Commons licence, unless indicated otherwise in a credit line to the material. If material is not included in the article's Creative Commons licence and your intended use is not permitted by statutory regulation or exceeds the permitted use, you will need to obtain permission directly from the copyright holder. To view a copy of this licence, visit http://creativecommons.org/licenses/by/4.0/.

\section{References}

Bauch C, Forster N, Loffing-Cueni D, Summa V, Verrey F (2003) Functional cooperation of epithelial heteromeric amino acid transporters expressed in madin-darby canine kidney cells. J Biol Chem 278:1316-1322 
Bauch C, Verrey F (2002) Apical heterodimeric cystine and cationic amino acid transporter expressed in MDCK cells. Am J Physiol Renal Physiol 283:F181-F189

Bertran J, Werner A, Chillaron J, Nunes V, Biber J, Testar X, Zorzano A, Estivill X, Murer H, Palacin M (1993) Expression cloning of a human renal cDNA that induces high affinity transport of L-cystine shared with dibasic amino acids in Xenopus oocytes. J Biol Chem 268:14842-14849

Bertran J, Werner A, Moore ML, Stange G, Markovich D, Biber J, Testar X, Zorzano A, Palacin M, Murer H (1992) Expression cloning of a cDNA from rabbit kidney cortex that induces a single transport system for cystine and dibasic and neutral amino acids. Proc Natl Acad Sci U S A 89:5601-5605

Bisceglia L, Purroy J, Jimenez-Vidal M, d'Adamo AP, Rousaud F, Beccia E, Penza R, Rizzoni G, Gallucci M, Palacin M, Gasparini P, Nunes V, Zelante L (2001) Cystinuria type I: identification of eight new mutations in SLC3A1. Kidney Int 59:1250-1256

Bröer A, Friedrich B, Wagner CA, Fillon S, Ganapathy V, Lang F, Bröer S (2001) Association of 4F2hc with light chains LAT1, LAT2 or y+LAT2 requires different domains. Biochem J 355:725-731

Bröer S (2008) Amino acid transport across mammalian intestinal and renal epithelia. Physiol Rev 88:249-286

Busch AE, Herzer T, Waldegger S, Schmidt F, Palacin M, Biber J, Markovich D, Murer H, Lang F (1994) Opposite directed currents induced by the transport of dibasic and neutral amino acids in Xenopus oocytes expressing the protein rBAT. J Biol Chem 269:25581-25586

Calonge MJ, Volpini V, Bisceglia L, Rousaud F, de Sanctis L, Beccia E, Zelante L, Testar X, Zorzano A, Estivill X, Gasparini P, Nunes V, Palacin M (1995) Genetic heterogeneity in cystinuria: the SLC3A1 gene is linked to type I but not to type III cystinuria. Proc Natl Acad Sci U S A 92:9667-9671

Casano AM, Albert M, Peri F (2016) Developmental Apoptosis Mediates Entry and Positioning of Microglia in the Zebrafish Brain. Cell Rep 16:897-906

Chairoungdua A, Segawa H, Kim JY, Miyamoto K, Haga H, Fukui Y, Mizoguchi K, Ito H, Takeda E, Endou H, Kanai Y (1999) Identification of an amino acid transporter associated with the cystinuria-related type II membrane glycoprotein. J Biol Chem 274:28845-28848

Chillaron J, Roca R, Valencia A, Zorzano A, Palacin M (2001) Heteromeric amino acid transporters: biochemistry, genetics, and physiology. Am J Physiol Renal Physiol 281:F995-F1018

Dave MH, Schulz N, Zecevic M, Wagner CA, Verrey F (2004) Expression of heteromeric amino acid transporters along the murine intestine. J Physiol 558:597-610

Dello Strologo L, Pras E, Pontesilli C, Beccia E, RicciBarbini V, de Sanctis L, Ponzone A, Gallucci M, Bisceglia L, Zelante L, Jimenez-Vidal M, Font M, Zorzano A, Rousaud F, Nunes V, Gasparini P, Palacín M, Rizzoni G (2002) Comparison between SLC3A1 and SLC7A9 cystinuria patients and carriers: a need for a new classification. J Am Soc Nephrol 13:2547-2553

Deora AB, Ghosh RN, Tate SS (1998) Progressive C-terminal deletions of the renal cystine transporter, NBAT, reveal a novel bimodal pattern of functional expression. J Biol Chem 273:32980-32987

Drummond I (2003) Making a zebrafish kidney: a tale of two tubes. Trends Cell Biol 13:357-365

Drummond IA (2000) The zebrafish pronephros: a genetic system for studies of kidney development. Pediatr Nephrol 14:428-435

Drummond IA (2004) Zebrafish kidney development. Methods Cell Biol 76:501-530

Drummond IA (2005) Kidney development and disease in the zebrafish. J Am Soc Nephrol 16:299-304

Egoshi KI, Akakura K, Kodama T, Ito H (2000) Identification of five novel SLC3A1 (rBAT) gene mutations in Japanese cystinuria. Kidney Int 57:25-32

Espino M, Font-Llitjos M, Vilches C, Salido E, Prat E, Lopez de Heredia M, Palacin M, Nunes V (2015) Digenic inheritance in cystinuria mouse model. PLoS One 10:e0137277

Feliubadalo L, Arbones ML, Manas S, Chillaron J, Visa J, Rodes M, Rousaud F, Zorzano A, Palacin M, Nunes V (2003) Slc7a9-deficient mice develop cystinuria non-I and cystine urolithiasis. Hum Mol Genet 12:2097-2108

Felsenstein J (1985) Confidence limits on phylogenies: An approach using the bootstrap. Evolution 39:783-791

Fernandez E, Carrascal M, Rousaud F, Abian J, Zorzano A, Palacin M, Chillaron J (2002) rBAT-b $(0,+)$ AT heterodimer is the main apical reabsorption system for cystine in the kidney. Am J Physiol Renal Physiol 283:F540-F548

Font MA, Feliubadalo L, Estivill X, Nunes V, Golomb E, Kreiss Y, Pras E, Bisceglia L, d'Adamo AP, Zelante L, Gasparini P, Bassi MT, George AL Jr, Manzoni M, Riboni M, Ballabio A, Borsani G, Reig N, Fernandez E, Zorzano A, Bertran J, Palacin M, International Cystinuria Consortium (2001) Functional analysis of mutations in SLC7A9, and genotype-phenotype correlation in non-Type I cystinuria. Hum Mol Genet 10:305-316

Fotiadis D, Kanai Y, Palacin M (2013) The SLC3 and SLC7 families of amino acid transporters. Mol Aspects Med 34:139-158

Franca R, Veljkovic E, Walter S, Wagner CA, Verrey F (2005) Heterodimeric amino acid transporter glycoprotein domains determining functional subunit association. Biochem J 388:435-443

Furriols M, Chillaron J, Mora C, Castello A, Bertran J, Camps M, Testar X, Vilaro S, Zorzano A, Palacin M (1993) rBAT, related to L-cysteine transport, is localized to the microvilli of proximal straight tubules, and its expression is regulated in kidney by development. J Biol Chem 268:27060-27068

Ganapathy V (2009) A traffic signal for heterodimeric amino acid transporters to transfer from the ER to the Golgi. Biochem J 417:e9-e11

Kandasamy P, Gyimesi G, Kanai Y, Hediger MA (2018) Amino acid transporters revisited: new views in health and disease. Trends Biochem Sci 43:752-789

Kudoh T, Tsang M, Hukriede NA, Chen X, Dedekian M, Clarke CJ, Kiang A, Schultz S, Epstein JA, Toyama R (2001) Dawid IB (2001) A gene expression screen in zebrafish embryogenesis. Genome Res 11:1979-1987

Kumar S, Stecher G, Tamura K (2016) MEGA7: Molecular Evolutionary Genetics Analysis version 7.0 for bigger datasets. Mol Biol Evol 33:1870-1874 
Lee WS, Wells RG, Sabbag RV, Mohandas TK, Hediger MA (1993) Cloning and chromosomal localization of a human kidney cDNA involved in cystine, dibasic, and neutral amino acid transport. J Clin Invest 91:1959-1963

Magagnin S, Bertran J, Werner A, Markovich D, Biber J, Palacin M, Murer H (1992) Poly(A)+ RNA from rabbit intestinal mucosa induces b0,+ and $\mathrm{y}+$ amino acid transport activities in Xenopus laevis oocytes. J Biol Chem 267:15384-15390

Miyamoto K, Katai K, Tatsumi S, Sone K, Segawa H, Yamamoto H, Taketani Y, Takada K, Morita K, Kanayama H, Kagawa S, Takeda E (1995) Mutations of the basic amino acid transporter gene associated with cystinuria. Biochem J 310:951-955

Mizoguchi K, Cha SH, Chairoungdua A, Kim DK, Shigeta Y, Matsuo H, Fukushima J, Awa Y, Akakura K, Goya T, Ito H, Endou H, Kanai Y (2001) Human cystinuria-related transporter: localization and functional characterization. Kidney Int 59:1821-1833

Mora C, Chillaron J, Calonge MJ, Forgo J, Testar X, Nunes V, Murer H, Zorzano A, Palacin M (1996) The rBAT gene is responsible for L-cystine uptake via the b0,(+)-like amino acid transport system in a "renal proximal tubular" cell line (OK cells). J Biol Chem 271:10569-10576

Ng AN, de Jong-Curtain TA, Mawdsley DJ, White SJ, Shin J, Appel B, Dong PD, Stainier DY, Heath JK (2005) Formation of the digestive system in zebrafish: III Intestinal Epithelium Morphogenesis. Dev Biol 286:114-135

Nguyen NTT, Vincens P, Roest Crollius H, Louis A (2018) Genomicus 2018: karyotype evolutionary trees and on-the-fly synteny computing. Nucleic Acids Res 46:D816-D822

Nitzan T, Rozenberg P, Cnaani A (2017) Differential expression of amino-acid transporters along the intestine of Mozambique tilapia (Oreochromis mossambicus) and the effect of water salinity and time after feeding. Aquaculture 472:71-75

Palacin M (1994) A new family of proteins (rBAT and 4F2hc) involved in cationic and zwitterionic amino acid transport: a tale of two proteins in search of a transport function. $\mathbf{J}$ Exp Biol 196:123-137

Palacin M, Fernandez E, Chillaron J, Zorzano A (2001) The amino acid transport system $\mathrm{b}(0,+)$ and cystinuria. Mol Membr Biol 18:21-26

Peters T, Thaete C, Wolf S, Popp A, Sedlmeier R, Grosse J, Nehls MC, Russ A, Schlueter V (2003) A mouse model for cystinuria type I. Hum Mol Genet 12:2109-2120

Petro-Sakuma C, Celino-Brady FT, Breves JP, Seale AP (2020) Growth hormone regulates intestinal gene expression of nutrient transporters in tilapia (Oreochromis mossambicus). Gen Comp Endocrinol 292:113464

Pfeiffer R, Loffing J, Rossier G, Bauch C, Meier C, Eggermann T, Loffing-Cueni D, Kuhn LC, Verrey F (1999) Luminal heterodimeric amino acid transporter defective in cystinuria. Mol Biol Cell 10:4135-4147

Pineda M, Wagner CA, Bröer A, Stehberger PA, Kaltenbach S, Gelpi JL, Martin Del Rio R, Zorzano A, Palacin M, Lang F, Bröer S (2004) Cystinuria-specific rBAT(R365W) mutation reveals two translocation pathways in the amino acid transporter rBAT-b0,+AT. Biochem J 377:665-674
Raciti D, Reggiani L, Geffers L, Jiang Q, Bacchion F, Subrizi AE, Clements D, Tindal C, Davidson DR, Kaissling B, Brandli AW (2008) Organization of the pronephric kidney revealed by large-scale gene expression mapping. Genome Biol 9:R84

Rauch GJ, Lyons DA, Middendorf I, Friedlander B, Arana N, Reyes T, Talbot WS (2003) Submission and Curation of Gene Expression Data. ZFIN Direct Data Submission (http://zfin.org). Accessed 9 June 2021

Reig N, Chillaron J, Bartoccioni P, Fernandez E, Bendahan A, Zorzano A, Kanner B, Palacin M, Bertran J (2002) The light subunit of system $b(0,+)$ is fully functional in the absence of the heavy subunit. EMBO J 21:4906-4914

Rius M, Sala L, Chillarón J (2016) The role of N-glycans and the C-terminal loop of the subunit rBAT in the biogenesis of the cystinuria-associated transporter. Biochem $\mathrm{J}$ 473:233-244

Rossi F, Casano AM, Henke K, Richter K, Peri F (2015) The SLC7A7 Transporter Identifies Microglial Precursors prior to Entry into the Brain. Cell Rep 11:1008-1017

Saitou N, Nei M (1987) The neighbor-joining method: A new method for reconstructing phylogenetic trees. Mol Biol Evol 4:406-425

Sakamoto S, Chairoungdua A, Nagamori S, Wiriyasermkul P, Promchan K, Tanaka H, Kimura T, Ueda T, Fujimura M, Shigeta Y, Naya Y, Akakura K, Ito H, Endou H, Ichikawa T, Kanai Y (2009) A novel role of the C-terminus of b0,+ AT in the ER-Golgi trafficking of the rBAT-b $0,+$ AT heterodimeric amino acid transporter. Biochem $\mathrm{J}$ 417:441-448

Seo HC, Drivenes Ø, Ellingsen S, Fjose A (1998) Expression of two zebrafish homologues of the murine Six3 gene demarcates the initial eye primordia. Mech Dev 73:45-57

Shen K, Sidik H, Talbot WS (2016) The Rag-Ragulator Complex Regulates Lysosome Function and Phagocytic Flux in Microglia. Cell Rep 14:547-559

Sievers F, Wilm A, Dineen D, Gibson TJ, Karplus K, Li W, Lopez R, McWilliam H, Remmert M, Söding J, Thompson JD, Higgins DG (2011) Fast, scalable generation of high-quality protein multiple sequence alignments using Clustal Omega. Mol Syst Biol 7:539

Stuart GW, McMurray JV, Westerfield M (1988) Replication, integration and stable germ-line transmission of foreign sequences injected into early zebrafish embryos. Development 103:403-412

Takayama K, Muto A, Kikuchi Y (2018) Leucine/glutamine and v-ATPase/lysosomal acidification via mTORC1 activation are required for position-dependent regeneration. Sci Rep 8:8278

Takesono A, Moger J, Farooq S, Cartwright E, Dawid IB, Wilson SW, Kudoh T (2012) Solute carrier family 3 member 2 (Slc3a2) controls yolk syncytial layer (YSL) formation by regulating microtubule networks in the zebrafish embryo. Proc Natl Acad Sci U S A 109:3371-3376

Tarifeno-Saldivia E, Lavergne A, Bernard A, Padamata K, Bergemann D, Voz ML, Manfroid I, Peers B (2017) Transcriptome analysis of pancreatic cells across distant species highlights novel important regulator genes. BMC Biol 15:21

Thisse B, Pflumio S, Fürthauer M, Loppin B, Heyer V, Degrave A, Woehl R, Lux A, Steffan T, Charbonnier XQ, Thisse C 
(2001) Expression of the zebrafish genome during embryogenesis (NIH R01 RR15402). ZFIN Direct Data Submission (http://zfin.org). Accessed 9 June 2021

Thisse B, Thisse C (2004) Fast Release Clones: A High Throughput Expression Analysis. ZFIN Direct Data Submission (http://zfin.org). Accessed 9 June 2021

Thisse C, Thisse B (2005) High Throughput Expression Analysis of ZF-Models Consortium Clones. ZFIN Direct Data Submission (http://zfin.org). Accessed 9 June 2021

Veljkovic E, Stasiuk S, Skelly PJ, Shoemaker CB, Verrey F (2004) Functional characterization of Caenorhabditis elegans heteromeric amino acid transporters. J Biol Chem 279:7655-7662

Verri T, Kottra G, Romano A, Tiso N, Peric M, Maffia M, Boll M, Argenton F, Daniel H, Storelli C (2003) Molecular and functional characterisation of the zebrafish (Danio rerio) PEPT1-type peptide transporter. FEBS Lett 549:115-122

Wagner CA, Lang F, Bröer S (2001) Function and structure of heterodimeric amino acid transporters. Am J Physiol Cell Physiol 281:C1077-C1093

Wang T, Wang X, Zhou H, Jiang H, Mai K, He G (2018) The Mitotic and Metabolic Effects of Phosphatidic Acid in the Primary Muscle Cells of Turbot (Scophthalmus maximus). Front Endocrinol (lausanne) 9:221

Waterhouse A, Bertoni M, Bienert S, Studer G, Tauriello G, Gumienny R, Heer FT, de Beer TAP, Rempfer C, Bordoli
L, Lepore R, Schwede T (2018) SWISS-MODEL: homology modelling of protein structures and complexes. Nucleic Acids Res 46:W296-W303

Weber E, Chevallier MR, Jund R (1988) Evolutionary relationship and secondary structure predictions in four transport proteins of Saccharomyces cerevisiae. J Mol Evol 27:341-350

Wingert RA, Selleck R, Yu J, Song HD, Chen Z, Song A, Zhou Y, Thisse B, Thisse C, McMahon AP, Davidson AJ (2007) The cdx genes and retinoic acid control the positioning and segmentation of the zebrafish pronephros. PLoS Genet 3:1922-1938

Yan R, Li Y, Shi Y, Zhou J, Lei J, Huang J, Zhou Q (2020) Cryo-EM structure of the human heteromeric amino acid transporter b0,+AT-rBAT. Sci Adv 6:eaay6379

Zuckerkandl E, Pauling L (1965) Evolutionary divergence and convergence in proteins. In: Bryson V, Vogel HJ (eds) Evolving Genes and Proteins. Academic Press, New York, pp 97-166

Publisher's note Springer Nature remains neutral with regard to jurisdictional claims in published maps and institutional affiliations. 